\title{
The Psychology of Letting Go
}

While ReCEnTLy REREADING The Duke's Children, the last volume of Anthony Trollope's Palliser series, I encountered the following remark: "Nothing will ever be quite what it used to be." ${ }^{\prime 1}$ Or, to paraphrase the title character in the movie The Big Lebowski, "Change abides."

Letting things go is simply one facet in the continuous process of change with which we all must deal: the "C-word." It seems reasonable to consider the situations that cause us to let things go and to examine the various reactions I have observed in myself and others in such circumstances. I hope that this analysis will not offend by pointing out the obvious. A little introspection is always useful, whether or not you share my perspective.

It is said that where one stands has a lot to do with where one sits. My context is, of course, the place where I have worked for the past 24 years. Because the Minnesota Historical Society (MHS) may be different in some respects from your place of employment, my issues and examples may not resonate entirely for you, but I suspect that you can draw the analogies. This is the situation in which I work: the MHS is a private organization with substantial public funding. It is a full-service cultural heritage organization with a complex set of programs: research library, manuscripts collections, the state archives, 26 museums and historic sites, publisher of 20-25 monographs per year and a quarterly journal, education outreach programs, the state historic preservation function, and a field archaeology program. There are around 700 employees, the equivalent of about 425 FTEs. As Deputy Director, all day-to-day activity reports through me.

Let's begin with a definition: letting go is what we do when a function, service, or activity previously performed is discontinued, when ongoing work is modified in so substantial a way that we perceive the resulting activity as fundamentally different, or when we lose tangible resources, such as colleagues.

I can imagine four situations when "letting go" happens; there may be others.

1. Anthony Trollope, The Duke's Children (Oxford, United Kingdom: Oxford University Press, 1999), 255 . 
We let something go to make time for other, existing tasks. We want to do fewer things simply so that we can devote more attention to those that remain, to do less with more, or to do it better. We rarely have the luxury to do this. We discontinue one activity to do something else instead: a change in priorities. We let go of a facet of some activity as part of a major revamping of how we carry out that work, or, the dreaded phrase "business process reengineering." We let go when colleagues leave, whether in the normal course of life-new jobs, retirement, death — or involuntarily — the end of a limited term project, or due to budget reductions.

\section{The Importance of Priorities}

Most of us quite naturally want some measure of say over our work lives, what we do, and how we do it.

Many of us find ourselves functioning in a work environment that is far more structured than it was years ago. My own institution places increasing emphasis on working within specific frameworks: coordination of action across programs, a focus on strategic plans, concentration on service to certain audiences, and achieving specific goals and outcomes. Staff are responding to priorities that are being set further and further up the organizational hierarchy. Multiple factors are driving this trend. Reduced institutional resources make for keener internal competition for funds. We also deal with the expectations of funders, internal and external, including granting agencies, foundations, philanthropies, and the public, who increasingly expect us to focus on meeting goals defined in terms of particular results, measureable outcomes, or definable benefits.

But the truth is that we have always lived within a set of priorities. Either we are active and set them for ourselves, or we are passive and allow others to set them for us, but we have to deal with them one way or the other. When the budget cuts or mission shifts come, you can be prepared with an understanding of what is most important and why—and act accordingly—or you can improvise.

Between 2003 and 2005, MHS faced a series of reductions that equaled about 16 percent of our operating budget. Unfortunately, we had no robust plan to guide us because we were an expansive organization that had been fortunate enough not to have faced the issue of contraction for years. When the next round of cuts came in 2008 and 2009, the institution was better prepared because we had spent time thinking about our institutional goals, audiences, programs, processes, and priorities. And when new funding actually appeared in 2010, we also knew where to focus dollars and staff. 


\section{What Compels Us to Let Things Go?}

Let us consider, first of all, reduced resources. Public budgets have been cut in all sectors. Endowments are down, and many foundations and philanthropies are focusing their attention on social issues. We are finding more interest in sponsorships, where corporate donations are tied to marketing opportunities, than in purely altruistic support for the civic and cultural life of the community.

But sometimes it is actually new, additional funding that force us to let something go. Our program receives a grant and we are required to provide some form of match. Something has to give way to get the work done. A further, complicating and frustrating factor is that new money seems to be directed chiefly toward specific, limited-term projects rather the support of ongoing work. At MHS, significant budget cuts to core programs on the one hand, and substantial new resources on the other, have created a catch-22: the new money may not be used legally to substitute for that which was lost.

Operating hours for historic sites were cut and most site managers would have been reduced to 75 percent time, but we have been able to redirect the remaining 25 percent of their work week toward new activities, such as joint programs with local libraries or involvement with schools in the national History Day competition. They had to let something go, though not always happily.

Sometimes there is a shift in institutional mission or focus, and we are caught up in the redirection of level funding into different programs or services. The most recent planning effort at MHS refocused the way we think about our work. There was a shift away from an emphasis on the services we provide-supporting research, publishing books, or creating museum exhibits — and a redirection toward the primary audiences we serve: students and teachers in grades $4-12$, adults over 50 , families with children, and young adults. The point here is not whether this new approach is right or wrong, better or worse. It is simply to observe that forces other than budget cuts can just as surely redefine our work.

Sometimes someone has an idea that there is a better way to do what we do. Operations are changed; things are done differently; some activities cease. Sometimes one's job status changes: perhaps a formal promotion or more project management and less hands-on work. Professionals often yearn for a time with a smaller staff, less public and organizational visibility, and simpler performance measures.

There are several reasons why, in an environment where our choices are increasingly set by others, we might react by accepting or even embracing "letting go." We might be disposed to do so, willing to let go and do something else because it makes sense 
to us. Or perhaps the change was our idea, and we have pride of ownership and the firm conviction that this must be right. Some people like challenge, and enjoy learning new skills, or realize that the "same old, same old" no longer excites them, and would like to try new approaches or methods. Sometimes letting go of the old allows you to make way for something that will advance your career, such as the realization that archivists would do well to learn Encoded Archival Description.

Other factors are less noble: realizing that change is necessary to stay employed, or responding to peer pressure, or what I refer to as the "Eyeore complex": just putting in your time, doing what you are told to do. This attitude might also be reflected in a "short timer attitude": counting the days until retirement, for example, or hoping that sooner or later, the organization will go back to the old way. A person who has gone through one too many strategic planning processes might well exhibit the attitude that they have been there and done that many, many times.

Alternately, rejecting and resisting letting go have many potential reasons. Sometimes, change simply does not make sense to us; the purposes for and advantages of doing so were not clearly explained or just do not make sense. We may also believe the change is wrong, the priorities it reflects are wrong, or that our ideas were better.

We may be responding to a feeling that these changes were not what we anticipated when we began our working lives. We do not enjoy them and have no aptitude for them. Sometimes colleagues leave institutions or retire when they feel this way. This response seems far more honest than the situation where someone hangs on until retirement, complaining endlessly.

A lack of institutional communication and shared mission can be at fault. For years at MHS, the processing staff often resisted change by insisting that the reference folks demanded they do something in a particular way even after the staff members in question had long since departed. Changes in reference service have pitted the interests of a large body of students and the historically-minded general public against a small cadre of academic and public historians who claim to be our most important customers. Balancing competing needs and audiences is always an important and complex issue, especially when change results in gains for one audience at the expense of another.

We may believe that everything we do is essential, and we cannot see how it is possible to discontinue anything. Or we may cling to the assertion that, as a professional, we get to decide what to do. Our status as tenured faculty or union membership may lead us to assert that "they" cannot change the way I work or what I do. I have not worked in an academic environment, but I have worked under civil service 
regulations and union contracts. I certainly understand the rationale for employee protections against unreasonable and arbitrary actions. But to me this legalistic response seems to suggest that one has no richer, intellectually robust, or practical counterargument to offer.

Sometimes we doubt our leaders, believing the boss makes bad decisions or is just changing things to feather his or her own nest. However, as we climb the organizational ladder, we may find ourselves becoming more tolerant of the motives and shortcomings of supervisors.

Finally, we may honestly and nobly believe that what we do has value, and we are good at meeting the public's needs, advancing scholarship, and the like. These are important thoughts, and perhaps the following ideas will help clarify.

\section{Five Strategies for Dealing with Letting Go}

1. Pick a strategy. Times of change are transitional zones. If you are unhappy about the direction that the organization is taking, you have to decide for yourself how you want to come out the other end of the tunnel. Do you want to be right in your opposition to this inappropriate turn of events and defend the high moral ground to the bitter end and at all cost, or do you want to manage the change successfully? Your chances of doing both are slim to nil. It is your decision how you will respond.

2. Acknowledge that there is a loss, even if you are in favor of the change, but certainly when you are unhappy about it. A thoughtful consultant I know who works with organizations undergoing change suggests holding a formal event to collectively acknowledge loss that comes with letting things go, even when you are in favor of the changes this reflects. Publicly acknowledging loss can help us move on just as a funeral does.

A review of Elisabeth Kubler-Ross's five stages of grief gives us examples that apply to any cause of grief, not just death. ${ }^{2}$

- Denial: "I feel fine." "This can't be happening, not to me."

- Anger: "Why me? It's not fair!" "Who is to blame?"

- Bargaining: "Can we postpone or minimize this?"

- Depression: "What's the point?"

- Acceptance: "It's going to be okay." "I can't fight it. I may as well prepare for it."

2. Elisabeth Kubler-Ross, (paraphrased from) On Death and Dying (New York: Simon and Schuster, 1969). 
3. Take control of the situation. Ask yourself, what can you do in a positive way to participate in the process and shape the outcomes?

4. Develop your repertoire. What new skills will I need to succeed: technical, managerial, operational? How can I acquire them?

5. Focus on the benefits. Any manager who wants you to let go of older ways and techniques better be able to articulate the benefits that will result. Insist on this. It might actually provide an opportunity for creative thinking. For example, it is difficult to perceive a positive benefit in having to reduce reading room hours. But we at MHS used this situation as an opportunity to improve service to specific audiences by creating a new schedule that actually added more evening and even Sunday hours for those who could not do their research between 9 and 5 on weekdays.

Change is constant. Though sometimes hard to acknowledge, in the end, how it works out in each of our lives is pretty much up to us. Good luck with letting things go.

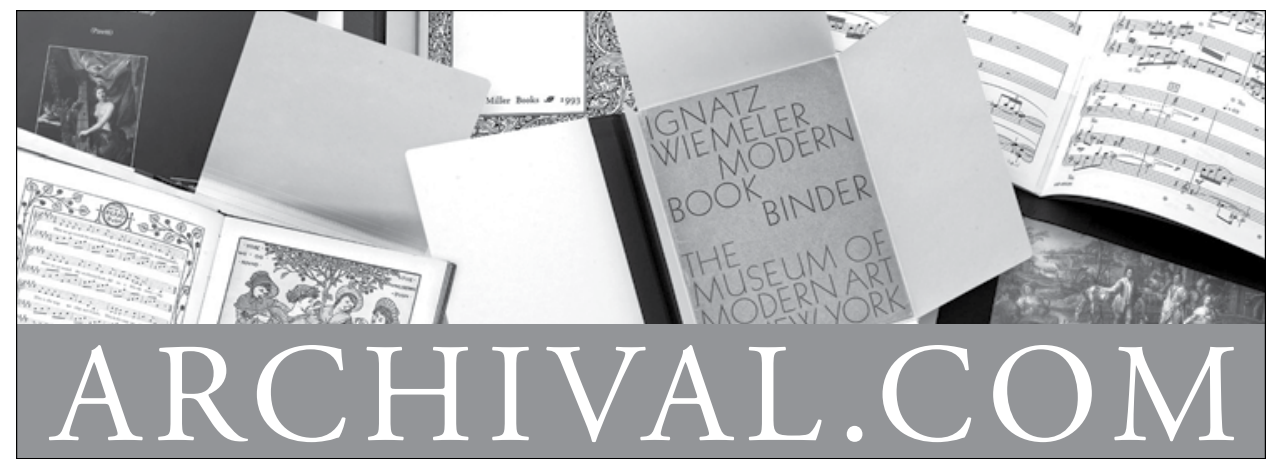

INNOVATIVE SOLUTIONS FOR PRESERVATION

Call for a complete catalog

Pamphlet Binders

Music Binders

Archival Folders

Manuscript Folders

Hinge Board Covers

Academy Folders

Newspaper/Map Folders

Bound Four Flap

Enclosures

Archival Binders
Polypropylene Sheet \& Photo Protectors Archival Boards

Adhesives

Bookkeeper

Century Boxes

Conservation Cloths

Non-Glare Polypropylene

Book Covers

CoLibri Book Cover System
ARCHIVAL PRODUCTS

P.O. Box 1413

Des Moines, Iowa 50306-1413

Phone: 800.526.5640

Fax: 888.220.2397

E-mail: custserv@archival.com

Web: archival.com 